\title{
Colégio Vasco da Gama: notas para pensar os entrelaçamentos das culturas escolares com as práticas esportivas
}

\author{
Carlus Augustus Jourand Correia* \\ José Cláudio Sooma Silva** \\ Antonio Jorge Gonçalves Soares***
}

\begin{abstract}
Resumo
O esporte e, mais especificamente, a prática esportiva no Brasil são elementos considerados pela sociedade como imprescindíveis para a construção de valores e da cidadania, assim como a escola. Além disso, o imaginário social sobre o atleta evidencia que, no Brasil, o esporte é muitas vezes encarado como uma promessa profissional, arregimentando muitos jovens para formação esportiva. Nesse processo, muitos precisam conciliar, muitas vezes com dificuldades, as rotinas escolares com as rotinas esportivas. $\mathrm{O}$ artigo apresenta os resultados obtidos num estudo sobre a escolarização de jovens atletas de alto rendimento no Colégio Vasco da Gama, inserido na agremiação esportiva homônima. Ancorado, principalmente, na utilização de instrumentos etnográficos de pesquisa, (entrevistas semiestruturadas e questionários) e na análise de documentos oficiais. O objetivo do artigo foi indiciar aspectos referentes aos possíveis entrelaçamentos das culturas escolares com as práticas esportivas na instituição de ensino. Os resultados da pesquisa sugerem que as relações entre o colégio e o clube interferem, decisivamente, nos saberes e práticas que, cotidianamente, são construídos através da interpenetração de elementos do esporte no espaço da escola. Juntamente com isso, foi identificado um sentimento de adesão à instituição escolar, por meio da linguagem do esporte.
\end{abstract}

Palavras-chave: Cultura Escolar. Escolarização. Esporte.

\footnotetext{
* Mestre em Educação pela Universidade Federal do Rio de Janeiro (UFRJ). Professor da Secretaria de Educação do Estado do Rio de Janeiro (SED-RJ).

** Doutor em Educação pela Universidade Estadual do Rio de Janeiro (UERJ). Professor da Faculdade de Educação da Federal do Rio de Janeiro (UFRJ).

*** Doutor em Educação Física pela Universidade Gama Filho (UGV). Professor da Faculdade de Educação da Federal do Rio de Janeiro (UFRJ).
}

PERSPECTIVA, Florianópolis, v. 35, n. 1, p. 188-213, jan./mar. 2017

http://www.perspectiva.ufsc.br 


\section{Introdução ${ }^{1}$}

O esporte no Brasil possui grande centralidade, influenciando aspectos econômicos, políticos e sociais. Aqui e em outras partes do mundo, o esporte é considerado pela sociedade como uma agência educativa, assim como a escola e até mesmo as instituições religiosas. $\mathrm{O}$ esporte e, mais especificamente, a prática esportiva no Brasil são elementos considerados ainda hoje imprescindíveis para a disciplinarização do corpo, desenvolvimento de capacidades motoras, construção de valores e da cidadania (GUEDES, 1999).

A centralidade conferida à prática esportiva no Brasil e no mundo transforma os atletas, principais atores desse espaço, em heróis e muitas vezes modelos a serem seguidos pelas crianças e jovens. Na lista de 2013 da Revista Forbes ${ }^{2}$, contendo as 100 maiores celebridades mundiais, foi constatado que havia 21 atletas. Junto aos atletas, estavam atores, músicos, diretores e produtores, personalidades, estrelas da TV, entre outros. Aliado a isso, o esporte é responsável por movimentar, na economia mundial, US\$ 1 trilhão, e os Estados Unidos lideram esse ranking, gerando cerca de US\$ 200 bilhões por ano. No Brasil, o valor investido anualmente é de cerca de R \$ 31 bilhões. Desse montante, somente o futebol movimenta mais de R $\$ 10$ bilhões ${ }^{3}$.

Com esses números, compreende-se a importância do esporte, como um potente gerador de empregos diretos e indiretos. A percepção da possibilidade de obtenção de capital econômico e social atrai, constantemente, muitos jovens para o esporte, na tentativa de profissionalização. Muitas vezes, eles são incentivados pelos próprios pais e por outros membros da família ou da sociedade em geral, que apoiam a formação esportiva dos jovens.

Devido a essa valorização do esporte no mundo, muitos jovens decidem ingressar nas mais variadas modalidades esportivas, com o objetivo de praticar uma atividade física e/ou se profissionalizar, evidenciando que no Brasil o esporte profissional é frequentemente visto como uma oportunidade de trabalho e de ascensão social e econômica (EPIPHANIO, 2002). Contudo, as relações entre o esporte e a educação não são marcadas por facilidades, tampouco por conciliações. A rigor, a concorrência entre o tempo esportivo e o escolar é muito comum no processo de formação de atletas de algumas modalidades esportivas brasileiras, tais como o futebol, o turfe e o atletismo.

A formação para o esporte de alto rendimento no Brasil não se desenvolveu no interior do sistema educacional, como ocorreu nos Estados Unidos, onde se procurou integrar dentro dos espaços 
escolares a formação esportiva, a escolarização básica e a universitária (SOARES et al, 2009). A consequência desse modelo apartado, no Brasil, foi que a escola e o clube se tornaram agências educativas independentes, que perseguem seus próprios objetivos. Enquanto a primeira almeja a formação escolar e a obtenção de capitais culturais, a segunda busca a formação esportiva e a obtenção de capitais corporais relacionados diretamente com uma modalidade esportiva específica. Assim, a escola e o clube apresentam lógicas de funcionamento que, muitas vezes, entram em conflito em função das diferentes exigências de formação. Com isso, os alunos-atletas no Brasil precisam operar com duas realidades formativas que, em certos casos, criam concorrência de tempo e de objetivos em suas vidas.

Nos Estados Unidos, por exemplo, o desenvolvimento dos esportes nas high schools e colleges remonta ao início do século XX, com a criação da National Collegiate Athletic Association. Na realidade esportiva americana, a detecção e o desenvolvimento dos futuros atletas ocorrem no interior das escolas primárias, atravessam as escolas de ensino médio e culminam nas universidades, de onde muitos alunos-atletas saem para compor as principais equipes dos mais variados esportes. Assim, desde a escola primária os jovens são incentivados a praticar esportes por meio da adesão às equipes esportivas e das competições mantidas por essas instituições escolares.

Para o funcionamento desse mecanismo simbiótico entre esporte e educação, dois fatores contribuem de forma decisiva. Primeiramente, existe nos Estados Unidos um circuito de competições regulares dentro dos condados, dos estados e do país que estimula a disputa esportiva entre as instituições de ensino. Além disso, por serem práticas esportivas realizadas dentro dos colégios e universidades, elas são adequadas e acomodadas ao horário escolar desses sujeitos, suavizando, em certa medida, a concorrência de tempo entre as atividades, estando também condicionadas diretamente ao bom desempenho acadêmico dos alunos.

Em alguns países da Europa, essa problemática sobre a conciliação entre a prática esportiva de alto rendimento e a educação vem sendo discutida e enfrentada, pelo menos, desde a década de 1950. A partir do diagnóstico da dificuldade em conciliar o esporte e a educação, muitos governos - como os da Finlândia, Dinamarca, Suécia e da extinta União Soviética - procuraram caminhos próprios para o desenvolvimento de estruturas que possibilitassem a integração entre essas duas atividades ou carreiras (METSA-TOKILA, 2002). 
A preocupação com o desenvolvimento escolar e esportivo dos atletas também foi sentida em outros países, como a Alemanha Oriental e a Polônia ${ }^{4}$. Apesar de algumas experiências não promoverem mudanças significativas na questão da conciliação entre profissionalização esportiva e escolarização para os jovens, o debate sobre esse dilema foi posto, pelo menos, desde a segunda metade do século XX. No Brasil, só mais recentemente esse problema foi identificado e entrou nas agendas governamentais, dos movimentos sociais e dos membros da sociedade civil (CORREIA, 2012).

Neste artigo apresentamos os resultados de uma pesquisa sobre a escolarização de jovens atletas do Colégio Vasco da Gama. O clube possui um colégio voltado para a educação básica, que atende atletas do $6^{\circ}$ ano do Ensino Fundamental até o $3^{\circ}$ ano do Ensino Médio. Essa experiência serviu para que nos aproximássemos tanto da temática sobre as rotinas esportivas e escolares de atletas de alto rendimento quanto das dificuldades e das possibilidades de conciliação entre essas duas carreiras nesta instituição de ensino.

O Colégio Vasco da Gama é um resultado recente da movimentação da sociedade civil para direcionar, mesmo que parcialmente, seus olhares para a formação escolar dos atletas das categorias de base. Constituída exclusivamente para atletas, a instituição responsabiliza o clube pelo acompanhamento da escolarização de seus atletas e busca criar mecanismos que possibilitem a conciliação entre o esporte e a escola, administrando as possíveis dificuldades decorrentes das tarefas exigidas por ambos, que devem ser cumpridas pelos jovens em formação (LUPO et al, 2014).

Esse Colégio não é a única iniciativa desse tipo no Brasil. Existem outros estabelecimentos de ensino mantidos por agremiações esportivas. Essas iniciativas de oferecimento de escolas para atletas, sejam espontâneas ou não, podem ser encaradas como resultado do recente debate gerado pela criação de legislação que responsabiliza os clubes esportivos pela formação de seus atletas. Nesse aspecto, podemos mencionar a criação da Lei n 12.395/2011, intitulada "Lei do Clube Formador", alterando a Lei $\mathrm{n}^{\circ}$ 9.615, de 24 de março de 1998 (Lei Pelé). A Lei n 12.395/2011 atribuí às entidades de prática esportiva a responsabilidade pelo ajuste do tempo destinado às atividades de formação esportiva aos horários do currículo escolar ou de curso profissionalizante, além da obrigatoriedade de propiciar ao atleta a matrícula escolar e de acompanhar sua frequência e aproveitamento na instituição de ensino (BRASIL, 2011).

Todavia, essas ações que emergiram recentemente buscam solucionar um problema estrutural na formação dos atletas brasileiros. Algo que, genericamente, pode ser chamado de "formação à 
brasileira". Por exemplo, a formação do atleta de futebol no Brasil prioriza a acumulação de capitais corporais e esportivos por meio de extensos treinamentos ao longo de vários dias da semana e em horários que, muitas vezes, podem entrar em conflito com o expediente escolar (DAMO, 2007). Estudos desenvolvidos por Melo (2010) evidenciam que, a contar da entrada na categoria de base até a chegada à equipe profissional de futebol, o atleta acumula aproximadamente 6.400 horas de treinos.

Em algumas modalidades, como é o caso do atletismo, do turfe e do futebol, índices pesquisados por Rocha (2013), Melo (2010) e Bartholo et al. (2011) indicam que o principal problema é a substancial parcela de tempo direcionada ao esporte e a progressiva concorrência entre o tempo dedicado ao treino e aquele dedicado à escola, ocasionando a secundarização do projeto de formação escolar e a migração de muitos desses alunos para o ensino noturno quando se mantém na escola Essa migração está diretamente relacionada às intensas rotinas de treinos nos turnos matutino e vespertino e à dificuldade de integração dos horários.

O progressivo aumento da carga de treino, à medida que os jovens avançam nas categorias de base, e a consequente migração para o ensino noturno como forma de acomodar a rotina dupla de atividades, acabam diminuindo a disposição desses sujeitos para a realização das atividades escolares e o interesse pelas aulas. Esses problemas são recorrentes, pois percebemos que a grande maioria desses alunos atletas está matriculada em instituições de ensino públicas e privadas que não possuem estrutura e currículos adaptados às especificidades de jovens inseridos no mundo do trabalho ou do esporte de alto rendimento ${ }^{5}$.

O interesse num estudo sobre o Colégio Vasco da Gama - com o foco direcionado para o indiciamento de possíveis entrelaçamentos das culturas escolares com as práticas esportivas - parte do entendimento desse espaço institucional como um local distinto do panorama delineado na formação esportiva brasileira. Nesse ponto, uma análise sobre a instituição, seus ritos, tradições, símbolos, tempos e espaços torna-se importante para compreender as formas como o colégio tenta conciliar as contradições intrínsecas à formação esportiva em concomitância com a formação escolar.

Este trabalho procura, portanto, indiciar algumas das apropriações/subversões feitas pelos sujeitos sociais do Colégio Vasco da Gama frente à instituição escolar, a priori pensada como possuidora de normas cristalizadas de ensino, hierarquia e usos do tempo e do espaço, mas que, a partir de um olhar mais apurado, permite-nos perceber elementos de negociação das rotinas escolares. A proposta do trabalho é mostrar que o projeto do Vasco da Gama para conciliação entre o esporte de alto 
rendimento e a escolarização não está apenas relacionado com processos de flexibilização das rotinas escolares (abono de falta/atrasos e remarcação de provas). Há, também, no interior dessa instituição a constituição de culturas escolares que se entrelaçam às práticas esportivas. Destarte, nesse Colégio, a forma escolar que se ancora na estipulação de regras, delimitação de espaços e tempos, prescrição de condutas, disciplinarização dos conhecimentos (VINCENT; LAHIRE; THIN, 2001) conhece diferentes contornos devido às práticas cotidianas dos sujeitos que buscam aproximar a escola das demandas do esporte.

Diante disso, serão realçados elementos que nos permitam indiciar como, no cotidiano do Colégio Vasco da Gama, são construídos mecanismos que procuram aproximar os objetivos esportivos do clube e dos atletas às demandas formativas da escola. Destacamos que essa escola intenciona produzir subjetividades que fujam das perspectivas hegemônicas instituídas na maioria das instituições escolares.

O presente trabalho, um estudo de caso de base etnográfica, teve como objeto uma escola voltada para atletas em formação totalmente financiada e montada por uma agremiação esportiva: o Colégio Vasco da Gama, situado em São Cristóvão, na Barreira do Vasco. Foram utilizadas como fontes: a análise documental do colégio, a observação participante, entrevistas realizadas na instituição e aplicação de questionários padronizados ${ }^{6}$ no sentido de investigar a complexidade e dinamicidade dos saberes e práticas escolares vivenciados pelos sujeitos sociais. Como sabemos, a preocupação do clube em que o colégio está inserido é a formação esportiva e demonstração de responsabilidade social com a escolarização de seus atletas. Sendo assim, em que medida as ações constituídas nesses espaços se alteram? Como se alteram? Como se estabelecem os possíveis entrelaçamentos das culturas escolares com as práticas esportivas nessa instituição de ensino?

\section{Culturas escolares e a construção das experiências: ajustando as lentes reflexivas}

Há, pelo menos, vinte anos, as culturas escolares vêm comparecendo no horizonte de preocupações daqueles que se interessam pela problematização do fenômeno da escolarização. Nessa linha, diferentes áreas do conhecimento educacional, (Pedagogia, Psicologia, Sociologia, Didática, Filosofia, História, por exemplo) a partir e em função de uma multiplicidade de abordagens e operações construídas, têm trabalhado com essa categoria histórica de análise (FARIA FILHO et al., 2004). 
Tanta ênfase despendida às culturas escolares, primeiramente, sinaliza para dois aspectos principais. O primeiro diz respeito à questão sobre os recortes semânticos empregados para ancorar um estudo, sob hipótese alguma, carregarem um repertório de significados próprios, imutáveis e universais, passível de ser utilizado indistintamente em variadas circunstâncias e épocas (DE CERTEAU, 1982, p. 104-5). Antes mais, as nomenclaturas, conceitos e categorizações são engendrados pelos sujeitos sociais em seus períodos históricos. Desta feita, realçar essas dimensões que nos permitem (ou nos obrigam!) pensar as culturas escolares como uma categoria histórica de análise significa, sobretudo, aceitar o desafio adicional de tentar precisar as potencialidades e as especificidades que justificam o seu emprego.

O segundo aspecto, por seu turno, condiz a determinada plataforma partilhada que esteve (e permanece) envolvida nessa aludida proliferação do comparecimento das culturas escolares na arena dos debates educacionais. Conquanto conheçam especificidades ${ }^{7}$, sua utilização gravita em torno da problematização de que, ao invés de se constituir como um mero lugar de reprodução daquilo que ocorre na sociedade em que está inserida, a escola incorpora e se apropria das necessidades, exigências e possibilidades sociais de cada período histórico, sobretudo, transformando-as. Por outras palavras, ao lado das ordens prescritivas, impositivas e disciplinares que se fazem presentes na forma escolar (VINCENT; LAHIRE; THIN, 2001), há todo um conjunto de experiências que conhece os seus "acasos dos começos" (FOUCAULT, 1988, p. 19) a partir do cotidiano vivenciado pelos sujeitos escolares (diretores, professores, alunos, outros profissionais etc.) (JULIA, 2001; CHERVEL, 1990; FORQUIN, 1993; VIÑAO FRAGO, 1995).

No que se refere às experiências, o retorno neste momento a Edward P. Thompson (1981) torna-se operatório. Para o historiador inglês, essa categoria de análise não tem sido explorada em todas as suas potencialidades. Isso porque, muitas vezes, acha-se aprisionada em quadros contextuais que concorrem por subsumir os sujeitos sociais em marcos cronológicos, direcionamentos políticos e econômicos; ou, em outras tantas, é perscrutada como alguma coisa que antecede as relações sociais que a impulsionariam.

O que descobrimos está num termo que falta: “experiência humana". [...] Os homens e as mulheres também retornam como sujeitos dentro desse termo - não como sujeitos autônomos, "indivíduos livres", mas como pessoas que experimentam suas situações e relações produtivas determinadas como necessidades e interesses e como antagonismos, e em seguida "tratam" essas experiências em suas consciências e suas culturas [...] das mais complexas maneiras [...]. (THOMPSON, 1981, p. 182). 
A precaução teórico-metodológica de Thompson em registrar que não compartilha da ideia de “indivíduos livres” apresenta-se como de fundamental importância. Afinal, o que está em consideração é a dupla - e indissociável - compreensão que pode (ou, mais ainda, deve) ser enfatizada pelo emprego da categoria de sujeitos sociais: as ações que são concretizadas por eles e, em concomitância, as sujeições e constrangimentos que os submetem. Neste ponto, muito mais do que uma investigação que se interesse em saber se as mulheres, os homens, as crianças possuem (ou não) experiências, o convite é para que as esquadrinhemos e as percebamos como impulsionadoras dos próprios sentidos e conotações que serão assumidos, disputados e negociados por esses sujeitos sociais em suas circunstâncias relacionadas ao viver cotidiano.

É mesmo significativo investigar o fenômeno da escolarização, acompanhados por aquilo que de estimulante e desafiador carregam os entrelaçamentos das culturas escolares com as experiências que são construídas pelos sujeitos sociais. Entrelaçamentos que são disparados a partir da complexa liturgia escolar que envolve os espaços e tempos e que podem ser perscrutados, por exemplo: na arquitetura (prédios especificamente construídos para abrigar escolas); no mobiliário (carteiras, lousa, giz, materiais didáticos etc.); nos livros escolares (manuais didáticos e editoras especializadas); nos rituais de avaliação (provas, testes, recuperações, aprovações e reprovações); nas prescrições curriculares (seleção de conteúdos, distribuição das disciplinas, cargas horárias); e, também, na relação dessas instituições com a comunidade que as cerca.

Com isso, mais do que uma janela para a sociedade ou um processo mecânico de reprodução da desigualdade social, a escola estabelece interlocuções com as possibilidades, necessidades e exigências sociais de cada período histórico. É, justamente, em função desse quadro de reflexões que, acreditamos, torna-se interessante incursionar sobre algumas das características que dizem respeito aos possíveis entrelaçamentos das culturas escolares com as práticas esportivas no Colégio Vasco da Gama.

\section{O clube e sua relação com o colégio}

O clube é uma instituição social. Frequentar e filiar-se a uma agremiação esportiva, especificamente um clube inserido no circuito de enfrentamentos futebolísticos espetacularizados, no Brasil, significa estabelecer um pertencimento a uma comunidade imaginada, na qual se constrói uma identidade específica em torno dessa instituição (HOBSBAWM, 1990). Isso implica pensar que o 
sistema de pertenças cria sugestões, constrangimentos e expectativas sobre determinadas atitudes dos sujeitos e dos grupos através de um universo de regras, tabus, crenças, tradições, etiquetas e rituais que definem o que é ser flamenguista, vascaíno, são-paulino ou corintiano. ${ }^{8}$

No caso do Vasco da Gama, temos uma agremiação esportiva voltada ao fomento de várias modalidades de esporte (remo, atletismo, natação, vôlei, basquete), mas que tem como principal vínculo de pertencimento o futebol. Apesar da proeminência do futebol como balizador das regras de funcionamento e da gestão do clube, esse espaço é um local de formação de atletas de todas as modalidades para a composição dos quadros profissionais dos esportes existentes no Vasco. A estruturação de equipes fortes e competitivas de qualquer modalidade no Vasco, como ocorre em qualquer clube, é condição fundamental para o fortalecimento da imagem daquela comunidade diante de outras no cenário esportivo regional e nacional. Dito isso, não devemos perder de vista que o Vasco da Gama é, acima de tudo, um clube voltado para o esporte e com aspirações de sucesso esportivo em diferentes níveis.

O Colégio Vasco da Gama, exclusivo para atletas do clube, está localizado no interior da agremiação. Ancorados nas percepções de Forquin (2000) e Viñao Frago (1995), devemos compreender que tanto o funcionamento dessa instituição quanto todo repertório de experiências que é vivenciado nos tempos e espaços escolares produzem efeitos e relações entre os sujeitos sociais desse colégio e a comunidade que o rodeia, influenciando diretamente, no caso, o clube Vasco da Gama.

Diante disso, vemos no espaço escolar uma influência da comunidade à sua volta (clube) sobre a formação dos seus símbolos, ritos, tempos e espaços. O funcionamento do colégio evidencia um relacionamento íntimo com a vida esportiva do clube. Em dias de jogos de futebol em São Januário, o colégio funciona em regime especial, com horário normal no turno da manhã, mas antecipado para às $16 \mathrm{~h}$ no turno da tarde. A justificativa para isso é que, em dias de jogos, o funcionamento convencional do clube é alterado e, desta maneira, o trânsito de alunos e professores no colégio pode interferir na organização do evento esportivo.

Ao longo de 2012 e $2013^{9}$, ocorreram em dias de semana, mais precisamente às quartas e quintas-feiras, respectivamente, 10 e 9 jogos em São Januário; assim, durante esses dias, os alunos do turno da tarde foram dispensados mais cedo. Esse quantitativo de perda de aula é irrisório para o calendário de aulas, que possui 208 dias letivos em sua pauta. No entanto, essa informação é 
interessante para mostrar e reforçar como a rotina do colégio sofre interferência direta por se situar nas dependências do clube de São Januário.

A relação estreita entre o cotidiano escolar e o funcionamento do clube não interfere apenas nos horários de entrada e saída dos alunos em dias de jogos. Essa interpenetração entre as instituições (clube e colégio) também pode ser verificada na organização administrativa e hierárquica do colégio, que está diretamente submetida à administração do clube e, consequentemente, aos interesses da presidência e de seus conselheiros.

No organograma do clube, a instituição de ensino pertence ao Departamento de Responsabilidade Social, e essas duas instâncias estão subordinadas à vice-presidência e à presidência do Vasco da Gama. Tanto o vice-presidente quanto os diretores de Responsabilidade Social são nomeados pela presidência do clube, ou seja, os responsáveis pela administração, controle e fiscalização do colégio são indicados diretamente pelo presidente sem nenhuma participação dos membros da comunidade escolar. Por serem cargos ocupados mediante nomeação, muitas vezes são usados dentro da dinâmica das agremiações esportivas brasileiras como moedas de troca para costurar alianças de poder, ou para aplacar momentaneamente as vozes internas dos grupos dissidentes (BURLAMAQUI, 2013).

No caso do Vasco da Gama, as questões políticas influenciam em demasia o funcionamento do colégio, pois essa unidade é mantida financeira e administrativamente pelo clube, sendo parte integrante de um de seus departamentos. Dessa forma, em determinados momentos, os problemas políticos e financeiros enfrentados pelo clube acabam interferindo na organização do colégio. Um dos casos que exemplificam essa questão ocorreu no final de 2012, quando o clube enfrentava uma grave crise financeira e muitos de seus conselheiros optaram por manter o orçamento do futebol intacto, à custa de cortes em outros setores, entre eles o colégio ${ }^{10}$.

$\mathrm{Na}$ disputa interna por recursos financeiros, aventou-se a possibilidade de fechar o estabelecimento de ensino para redirecionar suas verbas para outros setores esportivos. A pressão dos apoiadores do colégio foi forte e a solução encontrada pela diretora foi extinguir, no início de 2013, todas as turmas de Educação de Jovens e Adultos (EJA), desde o Ensino Fundamental até o Ensino Médio, a fim de promover equalização orçamentária no valor de $\mathrm{R} \$ 50 \mathrm{mil}^{11}$. Assim, o colégio fatalmente representa uma caixa de ressonância nesse cenário de crises esportivas no clube e disputas entre conselheiros, que questionam sua utilidade e função. 
Outro elemento que reforça a proximidade entre o espaço do colégio e o espaço do clube é a tentativa de transposição dos sentimentos de pertencimento e identidade existentes no clube para o lócus escolar. Parece-nos que essa construção leva o colégio a adotar aquilo que representa os sentimentos da comunidade, genericamente denominado "espírito vascaíno".

Dentro do colégio, essa relação com a identidade clubística perpassa pela imagem do escudo do Vasco, que está por toda a instituição. Em todas as salas de aula há escudos do Vasco colocados em cima dos quadros. Além das salas de aula, são encontrados nos telefones do clube, nos murais, nas garrafas d'água distribuídas aos alunos no recreio, nos uniformes dos atletas e no próprio símbolo de identificação do colégio. No verso dos cadernos fornecidos pelo clube aos alunos, constata-se ainda a presença do hino do clube.

A introdução desses símbolos imagéticos e gráficos no cotidiano escolar indica a aproximação íntima entre o colégio e o clube. Os escudos em diversos locais da instituição procuram evidenciar simbolicamente a simbiose entre o colégio e o clube, bem como a demarcação daquele espaço enquanto um local vascaíno. Juntamente com isso, a presença do hino no verso dos cadernos dos alunos sinaliza a tentativa de promover a identificação desses jovens com a instituição Vasco da Gama. Os símbolos da vascainidade estão presentes ostensivamente em todos os espaços do colégio.

Esses símbolos evidenciam os contatos estabelecidos entre o colégio e a comunidade à sua volta e ajudam na construção de um ethos, isto é, de uma marca que define essa instituição e sua missão para seus jovens atletas. Os elementos esportivos inerentes ao clube estão presentes na administração do cotidiano do colégio, na formação do seu currículo e nas apropriações sobre seu tempo e espaço. Algo que, estrategicamente, concorreria para a incorporação por parte dos alunos-atletas (no sentido mesmo de tornar corpo, esprit de corps) (VAGO, 2002) de todo um conjunto de símbolos e tradições referentes à agremiação.

\section{A cultura do esporte no colégio}

Para compreensão mais acurada do Colégio Vasco da Gama é preciso caracterizar minimamente esse espaço e seus sujeitos. Situado dentro do clube, esse colégio é uma instituição particular de ensino, construída e financiada exclusivamente com recursos do clube. 
Nos anos em que a pesquisa foi desenvolvida (2012 e 2013) a instituição de ensino contava com, respectivamente, 180 e 164 alunos, do $6^{\circ}$ ano do Ensino Fundamental ao $3^{\circ}$ ano do Ensino Médio, distribuídos em dois turnos (manhã e tarde). O Colégio Vasco da Gama é exclusivo para atletas em formação e, no período da pesquisa, existiam nove modalidades esportivas na instituição, a saber: futebol, atletismo, vôlei, remo, natação, basquete, futsal, jiu-jítsu e rúgbi. Apesar da grande variedade de modalidades existentes, há a predominância do futebol e do atletismo.

Mais de 3/4 do corpo discente do colégio era constituído de atletas do futebol e do atletismo. Além disso, o Colégio Vasco da Gama pode ser considerado um espaço predominantemente masculino, visto que $68,3 \%$ dos alunos eram do sexo masculino, enquanto $31,7 \%$ eram do sexo feminino ${ }^{12}$.Esse alto percentual de homens em detrimento de mulheres pode estar relacionado à grande quantidade de atletas do futebol no colégio (51\%), visto que este esporte, a despeito das conquistas contemporâneas na questão de gênero, ainda continua sendo um espaço principalmente masculino ${ }^{13}$. Apesar dessa ressalva, devemos lembrar que o esporte em geral, principalmente o de alto rendimento, ainda é um espaço de predominância masculina. Todavia, esse dado merece outras interpretações para além do campo esportivo, pois devemos situá-lo no contexto da educação de homens e mulheres na sociedade brasileira.

Outro índice interessante é que a maioria dos atletas provinha do estado do Rio de Janeiro (76,7\%); contudo, também existiam jovens $(23,3 \%)$ que migraram de outros estados da federação e até mesmo de outros países, como Japão e Portugal. São Paulo, Minas e Espírito Santo eram os principais pontos de saída de atletas, evidenciando uma movimentação maior de jovens no circuito da região Sudeste. Esses mesmos jovens indicavam que a região Sudeste é o melhor mercado para profissionalização, devido à quantidade de agremiações esportivas, projeção midiática e investimento financeiro.

A distribuição dos atletas dentro do próprio estado do Rio de Janeiro não era uniforme. Os jovens e suas famílias residiam em diversas localidades do estado, a maioria $(59,4 \%)$ no município do Rio de Janeiro, e os demais (40,6\%) em outros municípios. Esses índices nos mostram que o Colégio Vasco da Gama é um espaço marcado pela heterogeneidade dos alunos que, apesar de terem em comum o desejo de profissionalização no esporte, possuem trajetórias de vida muito diferentes. A heterogeneidade tem a ver com o próprio critério de seleção do talento esportivo, pois a busca do talento esportivo prescinde do local de moradia e da origem social dos atletas, mesmo que algumas 
modalidades esportivas operem com uma espécie de clivagem social. Sendo assim, a instituição de ensino em seu cotidiano precisa lidar com essas diferenças e criar elementos que aproximem minimamente a realidade e o interesse dos jovens; e o ponto de convergência é a carreira e o sucesso no esporte.

O elemento que aparece como principal aglutinador desses jovens em torno do colégio é a constituição de uma cultura esportiva na instituição, ou seja, um repertório de experiências que, ao ser enfatizado (no uniforme, nas paredes, nos cadernos, nas disciplinas etc.), torne o espaço escolar algo inteligível para eles e suas realidades. Como vimos anteriormente, as relações geográficas, administrativas e simbólicas do colégio com o clube aproximam a instituição escolar dos nexos e pertencimentos existentes no clube, principalmente no que se refere à valorização do esporte, visto que o Clube de Regatas Vasco da Gama é uma agremiação que tem como principal objetivo o fomento ao esporte e a formação de novos atletas. Sendo o Colégio Vasco da Gama um espaço exclusivo para alunos-atletas, não podemos deixar de destacar o papel dos sujeitos sociais, no caso os alunos, como importantes agentes também no fortalecimento dos entrelaçamentos das culturas escolares com as práticas esportivas na instituição. As experiências cotidianas desses alunos-atletas com o esporte e os códigos $^{14}$ oriundos desse campo acabam por construir expectativas com relação ao colégio e ao esporte.

Dito isso, sublinhamos que a constituição de todo um conjunto de experiências que remete às culturas escolares passa, impreterivelmente, pelos sujeitos sociais inseridos nos espaços e tempos escolares e na relação destes com a comunidade à sua volta (VIÑAO FRAGO, 1995). Dessa forma, embora as políticas educacionais forjadas em gabinetes e práticas educacionais utilitárias e conformadoras engendrem interferências nos estabelecimentos de ensino, acreditamos que circunstâncias de resistência, apropriação e negociação irrompam em meio a esses processos, dando visibilidade aos afazeres cotidianos do comportamento cultural nas unidades escolares.

Ao mergulhar no cotidiano do Colégio Vasco da Gama, percebemos um repertório de experiências escolares que conhece o seu momento de emersão a partir e em função de múltiplas negociações. Algo que, sobretudo, relaciona-se às acomodações de vários interesses conflitantes: as demandas de escolarização dos atletas; os interesses do clube em formar atletas de alto rendimento; as exigências dos órgãos públicos de educação que regulamentam e fiscalizam as instituições escolares, por exemplo. 
Nessa relação entre o colégio e clube do Vasco da Gama, precisamos entender que o primeiro está de certa forma subordinado aos interesses do segundo. O foco do clube é formar atletas, o que muitas vezes requer da instituição escolar um tipo de gestão de tempos de ensino e de avaliação que não entre em confronto com esta prioridade. No entanto, a finalidade da instituição educacional é promover o ensino-aprendizagem e a socialização dos sujeitos por meio da escolarização e socialização dos conhecimentos. Nesse sentido, o Colégio Vasco da Gama precisa adequar as suas funções sociais às expectativas do clube que a financia e às cobranças político-administrativas dos órgãos públicos que a fiscalizam. Sob essa variedade de interesses e expectativas, o estabelecimento de ensino se vê na obrigação de promover uma conciliação entre a cultura esportiva e os saberes e práticas escolares.

Acerca dessa conciliação, ao lado daquilo que já foi explorado, cumpre sublinhar ainda as características que estão presentes no uniforme usado pelos alunos. O escudo do Vasco da Gama está inserido no brasão do colégio, que se localiza no centro do uniforme escolar (em posição de destaque), reforçando a concepção de que o colégio é parte indissociável do clube. O uniforme se assemelha aos trajes esportivos, de modo que não há rupturas entre as vestimentas empregadas para a prática esportiva e aquelas utilizadas para frequentar o colégio.

A camisa é confeccionada em microfibra (também usada pelos jogadores de futebol profissionais), sendo leve e ventilada, podendo ser acompanhada de um jogging ou bermuda (todos com o símbolo do Vasco) e tênis para completar o uniforme escolar. O uso de calças jeans é permitido, porém observamos que foi pouco utilizada durante o período de realização do trabalho de campo (2012-2013).

O uniforme é um dos elementos constituintes da identidade de qualquer estabelecimento de ensino. Via de regra, essa estipulação do que é permitido (ou não) em termos de vestimenta dos alunos alude tanto a um esforço disciplinar orquestrado para padronizar comportamentos quanto a uma preocupação em enfatizar símbolos, ideais ou emblemas que, de algum modo, funcionem como estratégias para delimitar, homenagear e divulgar determinados aspectos que passam a ser concebidos como específicos para esta ou aquela instituição. Nessa linha, no caso do Colégio Vasco da Gama, a feição do uniforme, na qual se destacam características eminentemente esportivas, pode ser interpretada como mais um indício de que a cultura esportiva embaralha-se e confunde-se com os saberes, as práticas, as experiências, enfim, com a identidade mesma do colégio. Tais símbolos relembram permanentemente, a docentes e a atletas, que aquele é um espaço escolar de atletas e para atletas. 
Nesse quadro, não parece ser nada casual a tentativa de desenvolver outras normas e práticas curriculares que, de algum modo, estimulem uma relação de proximidade do aluno com o clube Vasco da Gama. Sobre esse ponto, de início, adquire significado importante o trânsito no clube e no colégio de muitos atletas profissionais do clube, ex-atletas e outros profissionais da área que realizam palestras mensais no horário letivo ${ }^{15}$ para os alunos, explicitando os desafios da carreira de esportista e, mais especificamente, as suas relações com o clube. As palestras não estão associadas diretamente a nenhuma disciplina ou rol de conhecimentos disciplinares, mas, devido à sua periodicidade e aproveitamento dentro do colégio, integram o currículo ${ }^{16}$, assim como a festa junina e a feira de ciências fazem parte do currículo de muitas escolas.

Essas palestras, com regularidade mensal (ocorrem geralmente na última terça ou quinta-feira de cada mês), procuram pontuar questões sobre o cuidado com o corpo, a superação de limites, a competitividade, o respeito pelo adversário e o que o clube representa no cenário do esporte nacional. Os palestrantes possuem perfis variados: ex-atletas ligados ao clube; ex-atletas sem sucesso que relatam as decisões equivocadas que tomaram; atletas em atividade; atletas que superaram dificuldades; e especialistas que dissertam sobre aspectos referentes à motivação, à educação financeira e à saúde. Destaque-se que essa parte do currículo apresenta um discurso de construção dos comportamentos esperados do aluno em formação esportiva no clube e informa o que deve ser uma boa gestão de carreira. De fato, a regularidade desses eventos com atletas profissionais, ex-atletas e especialistas indica como o colégio tem em seu currículo uma explícita vocação para escolarizar atletas.

Nesse ponto, é necessário compreender que o Colégio Vasco da Gama é completamente diferente das escolas para não atletas do Rio de Janeiro ${ }^{17}$. Por atender somente atletas, toda a sua estrutura de funcionamento busca estabelecer um processo de conciliação entre o tempo do colégio e o tempo do esporte, da forma menos traumática possível. A estruturação da instituição busca atender às especificidades e aos anseios desses atletas, bem como às demandas de cada modalidade esportiva. Isso faz com que os tempos e espaços escolares sejam bem diferentes da maioria das outras escolas, pois há maior flexibilização sobre as aulas e os seus tempos dentro da instituição. Observe-se que não é a flexibilização das normas e rotinas escolares que diferencia o Colégio Vasco da Gama das demais escolas, pois outras escolas, diante de necessidades individuais de alunos e responsáveis, também geram possibilidades de flexibilização. Todavia, a flexibilização nas escolas em geral depende de 
acordos não institucionalizados; no colégio do Vasco, a flexibilização, em função das necessidades do esporte ou do calendário esportivo, é institucionalizada.

Podemos dizer que o currículo está direcionado para o esporte, e até mesmo os horários de entrada e saída do colégio se norteiam pela preocupação com treinamentos e competições. No que tange aos horários dos alunos, para quem estuda no turno da manhã, o colégio inicia suas atividades sempre às $8 \mathrm{~h}$ e termina às $12 \mathrm{~h} 30$. No turno da tarde, as atividades do colégio iniciam às $13 \mathrm{~h} 40 \mathrm{e}$ terminam às $18 \mathrm{~h} 10$. Na parte da tarde, o horário de entrada é justificado pela rotina daqueles que treinam pela manhã, almoçam no clube e, logo após, dirigem-se ao colégio. Percebe-se que, tanto no turno da manhã quanto no turno da tarde, os horários são orientados em função das demandas dos treinamentos, seja com base nas supostas concepções dos especialistas em relação ao desempenho, seja com base na logística de deslocamento entre o treino e o colégio.

No regimento do colégio (datado de 2013), observamos a preocupação com o elemento esportivo por meio do respaldo científico dos especialistas em nutrição e em fisiologia do esporte. Nesse aspecto, o próprio funcionamento do colégio gira em torno de uma adaptação às questões esportivas e ao comportamento do corpo diante da necessidade de desenvolver atividades físicas e mentais durante todo o dia. A preocupação com as distâncias enfrentadas pelos alunos-atletas também é explícita no documento e mostra que a instituição de ensino conhece e compreende as dificuldades dos atletas com relação aos deslocamentos ${ }^{18}$ :

[...] muitos de nossos atletas estão distribuídos por várias regiões da cidade que não estão necessariamente próximas do clube ou não possuem fácil acesso a ela por questões de tráfego. A existência de um tempo demasiado no deslocamento dessas distâncias influencia no gasto de energia, concentração e consequentemente rendimento de nossos atletas. Desse modo, essa realidade de distâncias e deslocamentos deve ser considerada pelos departamentos do clube no nível de rendimento dos atletas. ${ }^{19}$

Todas essas questões sobre os tempos escolares nos fazem enxergar a influência da cultura esportiva sobre o cotidiano do Colégio Vasco da Gama. Mesmo que seja uma instituição escolar com interesses pedagógicos e educativos, procura acomodar as preocupações esportivas dos alunos, principalmente no que tange à gestão da carreira desde cedo e aos cuidados com o corpo, privilegiando a difícil equação entre a preservação da saúde e a maximização do rendimento esportivo. Essas adequações nos tempos escolares foram provenientes de negociações e debates que envolveram professores, profissionais do clube e até mesmo alunos, como explica a assistente social do clube: 
Trabalho há muito tempo aqui no colégio e nem sempre os alunos tinham esses horários de entrada e saída. Isso foi resultado de uma realidade que a gente vivia. Os alunos sempre chegavam atrasados, não rendiam tudo que podiam e eles mesmos reclamavam. Com muita luta conseguimos ajeitar esse horário da escola, que ficou melhor pra todo mundo (informação oral) ${ }^{20}$.

A fala da assistente social sinaliza que as apropriações dos tempos e, consequentemente, os diferentes aspectos referentes às culturas escolares não se restringem à aceitação das práticas que são realizadas comumente em outras instituições. Na verdade, é fato que os saberes da experiência, as contingências da vida e tantos outros conhecimentos não hierarquizados e contemplados oficialmente invadem e se mesclam aos afazeres diários das escolas, propiciando novas configurações ao espaço escolar. No caso do Colégio Vasco da Gama, os saberes ligados ao esporte e à educação, bem como as experiências cotidianas desses professores e alunos, ajudaram a estruturar uma organização e apropriação específica do tempo e a construção de um currículo voltado para as carreiras esportivas. Além da apropriação e subversão do tempo, o atravessamento da cultura esportiva na instituição também exerce influência sobre outros usos e desusos relacionados às circunstâncias do viver escolar.

Dentro do colégio, os espaços usados pelos alunos são praticamente os mesmos que existem nas escolas em geral, que não são direcionadas para atletas. Salas de aula com cadeiras enfileiradas, bibliotecas onde se prega o silêncio, laboratório de informática e quadra poliesportiva. No entanto, a diferença reside nas apropriações que os alunos e professores fazem sobre esses espaços estruturados fisicamente ao longo de suas aulas. Percebemos que muitas aulas de biologia, física, geografia, entre outras buscavam subverter a lógica da imobilidade e da disciplinarização dos corpos característica da sala de aula e dos bancos escolares ${ }^{21}$. Isso era realizado pelos professores como uma estratégia de ensino, como explicita uma das professoras:

Aqui no colégio nós sabemos que o aluno não gosta de ficar parado. Se aluno convencional já não consegue ficar 30 minutos sentado numa cadeira, imagina o garoto que é atleta, que trabalha com o corpo e tem essa coisa de fazer na prática. Aí nós, professores, buscamos nas aulas quebrar essa imobilidade e colocar os garotos para fazer o que mais gostam: se mexer e exercitar (informação oral) ${ }^{22}$.

A fala dessa professora (que também é uma ex-atleta de vôlei) evidencia a tentativa por parte de muitos professores de adequar suas aulas ao ethos dos alunos-atletas. Assim, ela enuncia a necessidade de variar o ambiente e as possibilidades metodológicas de ensino, de modo que se estimule a movimentação dos corpos dos atletas pelos espaços escolares. Sobre esses aspectos, observamos que o 
estudo do corpo humano se desenvolvia através da análise do esforço de um atleta de futebol num jogo, ou de um remador numa competição. O estudo da História do Brasil perpassava pela compreensão dos primeiros esportes existentes no país. As aulas de matemática e física relacionavam seus conteúdos sobre força, atrito, ângulos e cálculos à prática esportiva e à vida cotidiana desses atletas.

Ao lado disso, percebemos também em outras disciplinas a tentativa de descolamento do espaço tradicional da sala de aula. Nessa direção, alguns professores não priorizavam a sala de aula e optavam pela utilização de outras localidades do clube (arquibancada, quadra poliesportiva, pátio e até mesmo o entorno do clube) como estratégias didáticas. Essas práticas utilizadas pelos professores no Colégio Vasco da Gama mostram que, apesar do reconhecimento de sua importância no imaginário social, é preciso pensar a escola e as práticas que ali se efetivam também pelas brechas do instituído. Desse modo, devemos enxergar essas práticas dentro de uma concepção alargada da categoria de espaço escolar. Livres das percepções que o resumam ao intramuros do colégio, esses professores e alunos desenvolvem um processo de incorporação dos códigos do esporte, tão corriqueiros em suas vidas, para estabelecer negociações e paralelos com os conteúdos escolares.

Os usos diversificados desses espaços do colégio e do clube em relação às idealizações e projeções mostram que dentro dos sistemas e do que está (ou foi) instituído existem conflitos, fraturas, resistências e novas apropriações. Mesmo diante de estruturas e currículos consolidados, bem como de métodos homogeneizantes e burocráticos na organização do tempo-espaço, o esporte se sobressai e influencia, em grande parte, as ações cotidianas do Colégio Vasco da Gama. Há sempre terrenos porosos e abertos, suscetíveis de movimento; no caso da instituição estudada, essas ações caminham no sentido de criar uma conexão entre a realidade e os anseios esportivos desses jovens e as atribuições esperadas e requeridas pela escolarização em nossa sociedade.

A penetração da cultura esportiva também pode ser sentida na linguagem e nos valores difundidos no colégio. Na instituição de ensino, circula uma teia de significados e códigos utilizados em sala por professores, alunos e coordenadores que nos remetem ao esporte. Esses códigos linguísticos se encontram presentes no dia a dia do colégio, nos recados dados pelos funcionários ou no material utilizado pelos alunos em sala de aula.

Um exemplo disso foi a campanha contra o bullying intitulada: "Seja fairplay e diga não ao bullying". Sabemos bem que o termo fairplay é largamente difundido e utilizado pelos esportistas e que, no mundo dos esportes, significa aceitar voluntariamente as regras, jogar limpo, de forma cordial e 
justa. O conhecimento desse termo pela maioria dos alunos foi uma das motivações para seu uso na campanha contra o bullying, como relata uma das coordenadoras:

O slogan da campanha contra o bullying surgiu dos corredores do colégio mesmo. Aqui os alunos vivem com essa palavra na boca, principalmente quando estão comentando sobre os treinos ou as competições de que participam. Percebemos que era algo difundido e resolvemos usar para estreitar a comunicação (informação oral) ${ }^{23}$.

O relato da coordenadora revela como os códigos e significados dos esportes estão presentes na fala dos alunos e como possuem inteligibilidade entre eles. Dessa forma, percebemos que o colégio incorporou essa linguagem do mundo esportivo e a utilizou corriqueiramente como forma de comunicação com os sujeitos sociais do espaço escolar. Cabe lembrar que esses códigos são apropriados e reproduzidos ainda mais facilmente devido à ligação de muitos professores com uma vida esportiva pregressa. Mesmo que muitos não tenham se profissionalizado, o simples fato de terem experiência como atletas lhes permite conjugar essa linguagem dos alunos-atletas e, consequentemente, buscar a melhor maneira de integrar o interesse pelos esportes às aulas e aos conteúdos.

A linguagem e seus códigos são fundamentais na criação de uma cultura através das categorias conceituais comuns, aquelas que permitem a comunicação eficaz entre os membros, a definição de critérios de inclusão ou de exclusão e o estabelecimento de relações de intimidade e amizade. No caso do Vasco da Gama, o uso dessa linguagem que se apropria do esporte remonta à noção de que esses alunos compartilham esses códigos e os reconhecem enquanto portadores de algum significado. Essa linguagem e os códigos não são propagados de forma consciente e estratégica pelos alunos. Na verdade, tais códigos são fruto de uma intensa socialização desses sujeitos em espaços esportivizados, com vistas a criar e difundir signos ligados ao esporte e visões da realidade mediadas por tais experiências esportivas.

\section{Conclusão}

O estudo de algumas normas, experiências, saberes e práticas relacionadas ao viver cotidiano de alunos, professores, coordenadores e funcionários indiciou a presença de determinados códigos e valores que sinalizam para um total entrelaçamento entre as culturas escolares e as práticas esportivas no Colégio Vasco da Gama. Nesse sentido, podemos identificar todo um investimento voltado para a 
construção de uma identidade com o esporte, de forma mais ampla, e com o clube, de forma mais específica.

Desse modo, os espaços, a rotina e os tempos escolares são subvertidos segundo as demandas e a lógica esportiva que concedem privilégio ao corpo e à carreira de atleta. Nesse movimento, o currículo e as estratégias didáticas procuram dialogar com as atividades dos alunos fora do espaço escolar; os escudos presentes nas salas de aula, nos uniformes, nos telefones, nos murais, nas garrafas d'água distribuídas aos alunos buscam criar uma identidade esportiva para o colégio; as palestras mensais com atletas e ex-atletas anseiam inculcar lições de vida para suas carreiras; finalmente, a linguagem institucional almeja conectar-se com os signos e símbolos do esporte.

A análise desses elementos nos mostra que as experiências escolares não devem ser pensadas considerando-se apenas o processo formal de escolarização realizado nas salas de aulas ou laboratórios. Afinal, tais experiências também se desenvolvem nos corredores dos colégios, nos pátios, nos intervalos das aulas, nos recreios etc., evidenciando a importância de estendermos nossas reflexões para todos os espaços e tempos intra e extramuros das instituições de ensino.

No caso do Colégio Vasco da Gama, se bem atentarmos, ao lado disso que estamos denominando de processo formal de escolarização (ancorado em uma liturgia que envolve regras comportamentais; estipulação de tempos e espaços; divisão de matérias; baterias de avaliações etc.) há a presença de todo um conjunto - tão ou mais significativo - de ensinamentos que deve ser apreendido pelos alunos-atletas.

A orquestração desses ensinamentos por parte do Vasco da Gama, sob hipótese alguma, se afigura como livre de intencionalidades. Pelo contrário, sua constituição e desenho parecem incidir diretamente nos sujeitos escolares (alunos, professores e funcionários em geral), estabelecendo por meio de sua organização um determinado modo de desenvolvimento de habilidades e comportamentos, bem como disseminando e consolidando símbolos estéticos, culturais que, estrategicamente, tencionam modular aquilo que deve ser apreendido nas experiências cotidianas que lá são (ou deveriam ser) construídas. Algo, portanto, que passaria pelo esforço de ensinar aos alunos-atletas as formas ideais de viverem esportivamente, os meios adequados de superarem os obstáculos, as maneiras certas de lidarem com as frustrações, enfim, os modos corretos de praticarem o clube. 


\section{Notas}

${ }^{1}$ Esse artigo contou com apoio financeiro do Conselho Nacional de Desenvolvimento Científico e Tecnológico $(\mathrm{CNPq})$ e da Fundação de Amparo à Pesquisa do Estado do Rio de Janeiro (FAPERJ).

${ }^{2}$ Ver: <http://www.forbes.com/billionaires/list/>. Acessado em: 25 de abril de 2015.

${ }^{3}$ Ver: <http://oglobo.globo.com/brasil/brasil-movimenta-apenas-2-do-mercado-da-bola-13026765>. Acessado em: 27 de abril de 2015.

${ }^{4}$ Nesses países, devido à influência política da ex-URSS, identifica-se um modelo parecido com o soviético.

${ }^{5}$ Neste trabalho consideramos que a dedicação à profissionalização no esporte de alto rendimento é semelhante à inserção do sujeito no mercado de trabalho ordinário, visto o tempo empreendido e as obrigações a que ambas estão sujeitas.

${ }^{6}$ Esses questionários padronizados possuem perguntas fechadas que buscam respostas sobre o cotidiano escolar, esportivo e familiar dos jovens atletas. Para isso, foram construídas categorias como: rotina escolar; rotina esportiva; formação cultural familiar e nível socioeconômico da família. Esses dados foram coletados e processados estatisticamente no programa SPSS com vistas a criar um quadro geral dos atletas pesquisados.

${ }^{7}$ Dentro dos limites e recortes conferidos por este artigo, tais especificidades não serão abordadas. Para uma particularização delas, ver: Vidal (2005); Faria Filho et al (2004).

${ }^{8}$ Um episódio presenciado no interior do Clube Vasco da Gama exemplifica a potencialização dessas restrições e tabus. Na ocasião, um torcedor, conversando com outro, falou a palavra Flamengo em alto volume e foi observado por todos à sua volta. Fora do clube, a simples verbalização dessa palavra por um torcedor vascaíno, em um contexto desconhecido pelos ouvintes, não acarretaria tantos olhares recriminadores.

${ }^{9}$ Anos referentes à pesquisa realizada.

10 Essas informações foram reveladas também pela grande mídia no final de 2012. Disponível em: $<$ http://extra.globo.com/esporte/vasco/colegio-vasco-da-gama-demissoes-em-massa-ameaca-de-fechar-as-portas7140791.html>, acessado em: 28 dez. 2013, às $20 \mathrm{~h}$ e $31 \mathrm{~min}$.

${ }^{11}$ Para cortar gastos, a Educação de Jovens e Adultos foi fechada no colégio. Assim, todos os alunos da EJA passaram a fazer parte do ensino regular

${ }^{12}$ Todos os índices apresentados são provenientes de uma média ponderada dos percentuais verificados nos dois anos estudados (2012 -2013).

${ }^{13}$ Essa realidade masculina do futebol é tratada aqui para entendermos especificamente o caso do Brasil, pois se nos debruçarmos sobre outros países, como Estados Unidos, Suécia e Noruega, veremos o futebol como um esporte bem difundido entre as mulheres e menos carregado das representações masculinizantes.

${ }^{14}$ Entre os códigos existentes no esporte, podemos listar: a valorização pelo resultado, o estímulo à competição, a busca pelo desempenho, o desprezo por limites físicos e a honestidade. Apesar das variações existentes entre as modalidades, esses valores se encontram, de alguma forma, presentes em todos os esportes.

${ }^{15}$ Por serem realizadas no horário letivo, elas são de presença obrigatória para os alunos que estão no colégio naquele dia.

${ }^{16}$ Entendemos o currículo, nesse contexto, como toda experiência vivida no espaço escolar por seus sujeitos integrantes (professores, alunos, gestores, funcionários, comunidade e pais), mediada por saberes disciplinares, pelo acervo material e simbólico, pela arquitetura escolar, pelos eventos escolares, pelas normas e por tudo que constitui essas experiências na formação de uma cultura que orienta os sujeitos naquele espaço.

${ }^{17}$ Essas escolas ditas para não atletas são aquelas que na atualidade não possuem um currículo e mecanismos adaptados às especificidades da rotina de treinos dos atletas. No entanto, o funcionamento dessas escolas não dificulta apenas a escolarização dos atletas, mas também dos jovens trabalhadores, pois estes não se veem contemplados por instituições de ensino que compreendam suas realidades específicas.

18 Índices coletados por meio de questionários aplicados no trabalho de campo mostram que $44,5 \%$ dos atletas moram a mais de $10 \mathrm{~km}$ do clube. Dentre os $55,5 \%$ que moram a menos de $10 \mathrm{~km}$ do clube, $62,4 \%$ são do futebol e moram nas dependências do clube. Dessa forma, muitos moram a distâncias superiores a $10 \mathrm{~km}$ do clube.

${ }^{19}$ Relatório de 10/05/2010 do departamento médico para distribuição e conhecimento de todos os outros departamentos do clube.

${ }^{20}$ Entrevista com Simone (nome fictício), assistente social do Colégio Vasco da Gama, em 01/10/2012.

${ }^{21}$ Não desconsideramos que, tanto no processo de formação esportiva do Clube Vasco da Gama quanto no seu Colégio, os alunos-atletas sejam muitas vezes tolhidos de certas práticas. No entanto, mesmo levando em

PERSPECTIVA, Florianópolis, v. 35, n. 1, p. 188-213, jan./mar. 2017

http://www.perspectiva.ufsc.br 
consideração esse tolhimento, durante o trabalho de campo, nos despertou bastante interesse essa preocupação manifestada por alguns professores em subverter a lógica da imobilidade, ansiando, assim, aproximar o conteúdo programático das disciplinas das realidades dos alunos-atletas.

${ }_{22}$ Entrevista com Lídia (nome fictício), professora do Colégio Vasco da Gama, em 13/11/2012.

${ }^{23}$ Entrevista com Lurdes (nome fictício), coordenadora do Colégio Vasco da Gama, em 16/05/2013.

\section{REFERÊNCIAS}

BARTHOLO, Thiago Lisboa. et al. Formando jogadores de futebol:o impacto do tempo de treinamento na formação escolar de jovens espanhóis e brasileiros. In: CONGRESSO BRASILEIRO DE CIÊNCIAS DO ESPORTE, 17, 2011, Porto Alegre. Anais... Porto Alegre: UFRGS, 2011. p. 1-14.

BRASIL. Lei n ${ }^{\circ} 12.395$, de 16 de março de 2011. Altera as Leis nos 9.615, de 24 de março de 1998, que institui normas gerais sobre desporto, e 10.891, de 9 de julho de 2004, que institui a Bolsa-Atleta; revoga a Lei n⿳o 6.354, de 2 de setembro de 1976; e dá outras providências. Diário Oficial [da] República Federativa do Brasil, Brasília, DF, 17 mar. 2011. p.1.

BRASIL. Decreto ${ }^{\circ} 138.54$, de 17 de julho de 2014. Dispõe sobre o funcionamento das unidades escolares assistidas pelos programas do Ginásio experimental carioca e ginásio experimental olímpico e paraolímpico e concede outras providências. Diário Oficial [do] município do Rio de Janeiro, Rio de Janeiro, RJ, v. 53, n. 542, 17 jul. 2014. Seção 2, p. 27

BURLAMAQUI, Luiz Guilherme. A outra razão: os dirigentes de futebol entre práticas e representações. 2013. 232f. Dissertação (Mestrado em História) - Programa de Pós-Graduação em História, Universidade Federal Fluminense, Niterói, 2013.

CHERVEL, André. História das disciplinas escolares: reflexões sobre um campo de pesquisa. Teoria \& Educação, Porto Alegre, v. 2, p. 177-229, 1990.

CORREIA, Carlus Augustus Jourand. Disputas em campo: políticas públicas na relação entre futebol e educação e seus impactos sobre jovens atletas. 2012. 63f. Trabalho de Conclusão de Curso (Especialização em Educação) - Programa de Pós-Graduação em Educação, Universidade Federal do Rio de Janeiro, Rio de Janeiro, 2012.

DAMO, Arlei Sander. Do dom à profissão: formação de futebolistas no Brasil e na França. São Paulo: Aderaldo e Rothschild, 2007.

DE CERTEAU, Michel. A escrita da história. Rio de Janeiro: Forense Universitária, 1982.

EPIPHANIO, Erika Höfling. Conflitos vivenciados por atletas quanto à manutenção da prática esportiva de alto rendimento. Revista Estudos de Psicologia, Campinas, PUC, v. 19, n. 21, p. 15-22, jan.-abr.,2002. 
FARIA FILHO, Luciano Mendes de. et al. A cultura escolar como categoria de análise e como campo de investigação na história da educação brasileira. Educação \& Pesquisa, São Paulo, USP, v. 30, n. 1, p. 139-159, jan./abr. 2004.

FORQUIN, Jean Claude. Escola e cultura: as bases sociais e epistemológicas do conhecimento escolar. Educação em Revista, Belo Horizonte, UFMG, v. 20, n. 18, p.138-146, dez. 1993/jun. 1994.

. O currículo entre o relativismo e o universalismo. Revista Educação \& Sociedade. Campinas, Unicamp, v.12, n.73, p. 47-70, dez. 2000.

FOUCAULT, Michel. Microfísica do Poder. Rio de Janeiro: Graal, 1988.

FRAGO, Viñao Antônio. Historia de la educación e historia cultural: posibilidades, problemas, cuestiones. Revista Brasileira de Educação, São Paulo, Anped, n. 0, p. 63-82, set./dez 1995.

. El espacio y el tiempo escolares como objecto histórico. Contemporaneidade e Educação, Rio de Janeiro, Instituto de Estudos da Cultura Escolar, v. 5, n. 7, p. 93-110, jul. 2000.

GEERTZ, Clifford. A interpretação das culturas. Rio de Janeiro: Zahar Editores, 1978.

GUEDES, Dartagnan Pinto. Educação para a saúde mediante programas de Educação Física escolar. Revista Motriz, São Paulo, UNESP, v. 5, n. 1, p. 10-16, jun.1999.

HOBSBAWM, Eric. Nações e Nacionalismos desde 1780: Programa, mito e realidade. Rio de Janeiro: Paz e Terra, 1990.

JULIA, Dominique. A cultura escolar como objeto histórico. Revista Brasileira de História da Educação, Campinas, SBHE, v.1, n. 1, p. 9-44, jan./jun. 2001.

LUPO, Corrado. et al. Motivation towards dual career of European student-athetles. European Journal of sport Science, Turim, s/n, p. 1-10, ago. 2014.

MELO, Leonardo Bernardes. Silva. Formação e escolarização de jogadores de futebol do Estado do Rio de Janeiro. 2010, 75f. Dissertação (Mestrado em Educação Física) - Programa de Pós-Graduação em Educação Física, Universidade Gama Filho, Rio de Janeiro, 2010.

METSA-TOKILA, Timo. Combining competitive sports and education: how top-level sport became part of the school system in the Soviet Union, Sweden and Finland. European Physical Education Review, Londres, London University, v. 8, n. 3, p. 196-206, jan./jun. 2002.

ROCHA, Hugo Paula Almeida. A escola dos jóqueis: a escolha da carreira do aluno atleta. 2013. $241 \mathrm{f}$. Dissertação (Mestrado em Educação) - Programa de Pós-Graduação em Educação, Universidade Federal do Rio de Janeiro, Rio de Janeiro, 2013. 
SOARES, Antonio Jorge Gonçalves. et al. Mercado do futebol, juventude e escola. Revista Juventude.Br, São Paulo, Centro de Estudos e Memória da Juventude, v. 8, p. 36-39, 2009.

THOMPSON, Edward Palmer. A miséria da teoria. Rio de Janeiro: Zahar Editores, 1981.

VAGO, Tarcísio Mauro. Cultura Escolar, Cultivo de Corpos: educação physica e Gymnastica como práticas constitutivas dos corpos de crianças no ensino público primário de Belo Horizonte (19061920). Bragança Paulista: EDUSF, 2002.

VIDAL, Diana Gonçalves. Culturas escolares: estudo sobre práticas de leitura e escrita na escola pública primária (Brasil e França, final do século XIX). Campinas: Autores Associados, 2005.

VINCENT, Guy; LAHIRE, Bernard; THIN, Daniel. Sobre a história e a teoria da forma escolar. Educação em Revista, Belo Horizonte, jun., 2001, p. 7-48, 2001. 


\section{College Vasco da Gama Notes for considering the interlinking of school cultures with sports}

\begin{abstract}
Sport, and more specifically, the practice of sports in Brazil, are elements considered by society as essential to the construction of values and citizenship, as is schooling. In addition, the social imaginary of the athlete shows that in Brazil sport is often seen as a professional opportunity, and many young people are encouraged to enter athletic training programs. In this process, many youth need to reconcile school routines with sports routines and often confront difficulties doing so. The article presents the results of a study on the education of young high-performance athletes at the Colégio Vasco da Gama school, which is associated to the private sports club with the same name. Based principally on the use of ethnographic research tools (semi-structured interviews, and questionnaires) and on the analysis of official documents, the purpose of the article was to identify connections of school culture with sports activities at this educational institution. The research results suggest that the relationship between the school and the club interfere decisively in the knowledge and practices that are constructed in the daily activities through the penetration of sport elements in school space. Moreover, a sense of belonging to the school institution was identified by means of sports language..
\end{abstract}

Keywords: School Culture. Schooling. Sport.

\section{Colegio Vasco da Gama: notas para pensar el entrelazamiento de culturas escolares con prácticas deportivas}

\section{Resumen}

El deporte, y más concretamente, la práctica del deporte en Brasil son elementos considerados por la sociedad como algo esencial para la construcción de valores y la ciudadanía, así como la escuela. Además, el imaginario social del atleta muestra que en Brasil el deporte es a menudo visto como una promesa profesional, reuniendo a muchos jóvenes a la formación deportiva. En el proceso, muchos necesitan conciliar, a menudo con dificultades, rutinas escolares con rutinas deportivas. El artículo presenta los resultados de un estudio sobre la educación de los jóvenes deportistas de alto nivel en el Colegio Vasco da Gama, que se encuentra en la universidad deportiva del mismo nombre. Anclado principalmente en el uso de instrumentos de investigación etnográfica, (entrevistas semiestructuradas y cuestionarios) y en el análisis de documentos oficiales. El propósito del artículo fue para indicar aspectos relativos a las posibles relaciones de las culturas escolares con las actividades deportivas en la institución educativa. Los resultados del estudio sugieren que la relación entre la escuela y el club interfiere de manera decisiva en el conocimiento y las prácticas que, cada día, se construyen por la interpenetración de elementos deportivos en las instalaciones de la escuela. Junto con esto, un sentido de pertenencia a la institución escolar fue identificado a través del lenguaje del deporte.

Palabras clave: Cultura Escolar. Escolarización. Deporte. 


\section{Carlus Augustus Jourand Correia}

E-mail: cabelovf@hotmail.com

José Cláudio Sooma Silva

E-mail: claudiosooma@gmail.com

Antonio Jorge Gonçalves Soares

E-mail: ajgsoares@gmail.com
Recebido em: 03/09/2015

Aprovado em: 15/09/2016 